\title{
Single Nucleotide Polymorphism
}

National Cancer Institute

\section{Source}

National Cancer Institute. Single Nucleotide Polymorphism. NCI Thesaurus. Code C18279.

A variation of a single nucleotide at a specific location of the genome due to base substitution, present at an appreciable frequency between individuals of a single interbreeding population. 